\title{
Driving Factors of Organizational Innovation
}

\author{
Pedro Carlos Resende Junior \\ University of Brasilia, Brasilia, Brazil \\ Antonia Regina de Oliveira \\ Corporate University of Brazilian Post, Brazil \\ Ricardo Ken Fujihara \\ University of Brasilia, Brasilia, Brazil
}

\begin{abstract}
This article seeks to outline the main driving factors of organizational innovation within 19 Brazilian companies from both the public and private spheres, whose performances have stood out at national level. The study comprises one of the stages of $A_{\mathrm{PMN}} \mathrm{I}$, an assessment methodology for prizes, which emerged from the need for the National Quality Foundation's (FNQ) Technical Group for Innovation to disseminate the concept of innovation management to Brazilian organizations and universities. The technical group, coordinated by the FNQ and the Getúlio Vargas Foundation - FGV/EAESP, is made up of the following organizations: AES, Ampla, Brasilata, Cemig, Coelba, Correios, Cummins, EDP, Embraer, FGV, Fibria, Fleury, GPC Química, Itaú, Natura, Promon, Senac, Senai, and Volvo. The problem-situation discussed is that these organizations have different models, dimensions, factors, and scales for assessing innovation management, thus making it necessary to identify in the sample the common factors that drive organizational innovation.
\end{abstract}

Keywords: innovation, management, factorial

\section{Introduction}

The problem-situation discussed is that high-level performance Brazilian companies have different models, dimensions, factors, and scales for assessing innovation management, thus making it necessary to identify in the sample the common factors that drive organizational innovation. According to the Organization for Economic Cooperation and Development (OECD, 2005), the implementation of new work methods that introduce significant changes within organizational structures is seen as one of the perspectives of innovation. According to Birkinshaw, Hamel, and Mol (2008), organizational innovation in public sector organizations refers to the application of a management practice, process, structure, or technique, which is new for the state of art and contributes towards reaching strategies, objectives, and organizational targets.

This article seeks to outline the main driving factors of organizational innovation within 19 high-level performance Brazilian companies. The study emerged from the need for the National Quality Foundation's (FNQ) to develop and disseminate the construct of innovation management to Brazilian organizations and universities. The technical group, coordinated by the FNQ and the Getúlio Vargas Foundation - FGV/EAESP,

Pedro Carlos Resende Junior, Professor, Ph.D., Post-graduation in Administration, University of Brasilia. Email: pcrj73@gmail.com.

Antonia Regina de Oliveira, Statistician, Corporate University of Brazilian Post.

Ricardo Ken Fujihara, Master, Administration, University of Brasilia. 
is made up of the following organizations: AES, Ampla, Brasilata, Cemig, Coelba, Correios, Cummins, EDP, Embraer, FGV, Fibria, Fleury, GPC Química, Itaú, Natura, Promon, Senac, Senai, and Volvo.

The methodology for assessing innovation models resulted from the need for FNQ's Technical Group for Innovation to disseminate the concept of innovation management to Brazilian organizations and universities by structuring a study group composed of leading organizations in the domain. The $\mathrm{A}_{\mathrm{PMN}} \mathrm{I}$ methodology consists of four sections: research preparation, theoretical research, empirical research, and evaluation of results. The complete process involves 22 stages, as shown in Figure 1, though it can be carried out in modules. This article discusses the results from Stage 14.

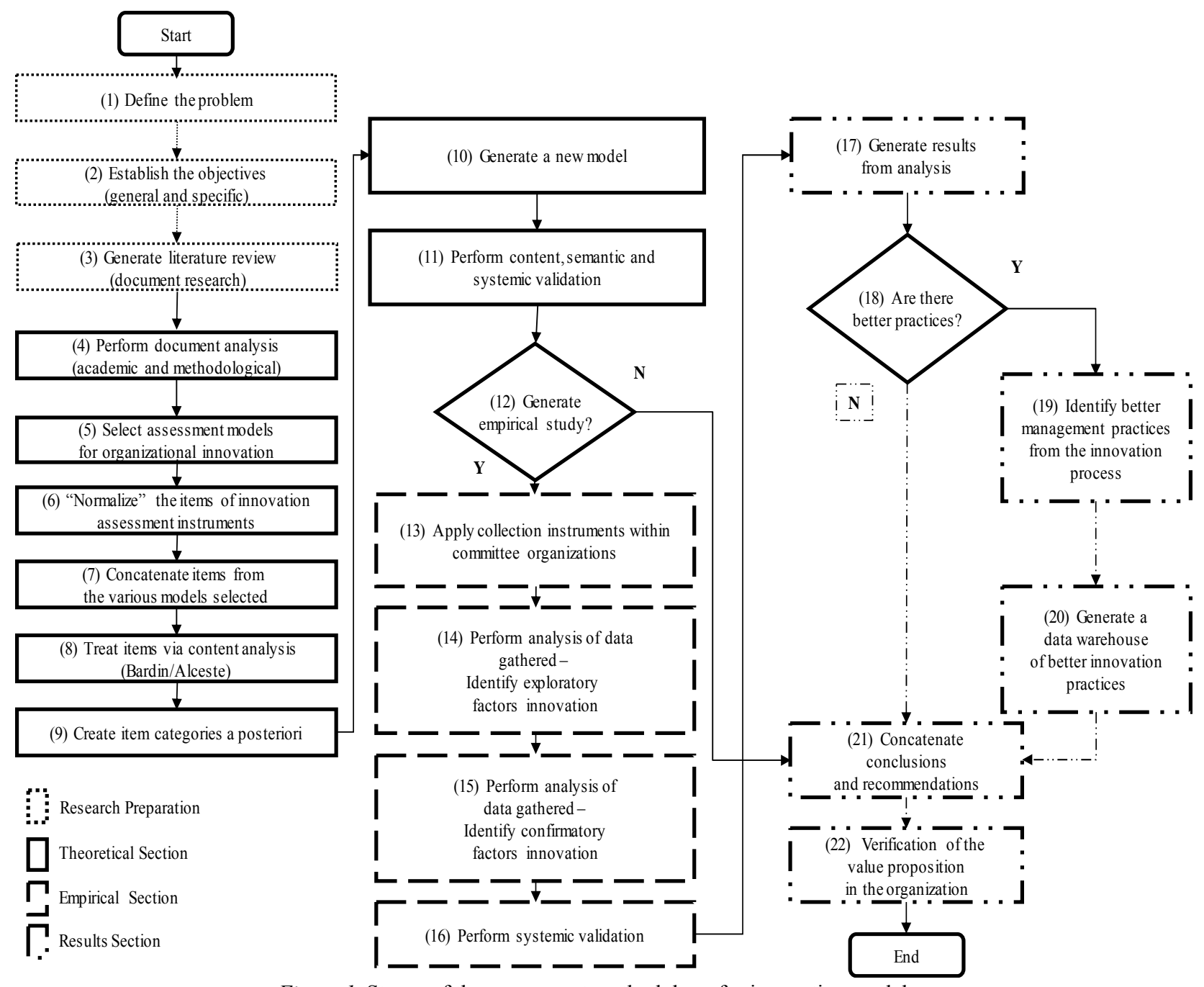

Figure 1. Stages of the assessment methodology for innovation models.

\section{Methodology}

The study adopted a mixed approach, drawing on qualitative and quantitative techniques for data collection and analysis. A literature review was carried out, of books, annals from conferences, published dissertations and theses, as well as national and international periodicals. Furthermore, contact was maintained with researchers and specialists from other technical FNQ groups, universities, and research centers. 


\section{Development of Collection Instrument}

The following were used in order to develop items from the scale: (1) document analysis, with attention paid to the references relating to each model, norm, and prize identified; (2) interviews with specialists; and (3) descriptions of the organizations' features that either stimulate or are conducive to innovation. The criteria outlined by Pasquali (2010) were applied. Thus, the research sought, in each item, descriptions of clear and precise actions, expressing a single idea, using simple and short sentences. Care was taken to avoid ambiguous, overly technical, atypical, or negative expressions.

Content, semantic, and systemic validations of questionnaire items were carried out in line with the criteria suggested by Pasquali (2010) and Hair, Black, Babin, Anderson, and Tatham (2009), so as to guarantee that each measurement item would point to an observable, explicit, and clear action, taking into account the setting's social variables or resources needed for the object of the action.

Content validation was performed by judges, as Hernandéz-Nieto (2002) suggested, followed by semantic and statistical validation. In this study, "judges" denote field specialists with expertise to validate the construct and context under research. The aim of content validation is to confirm, in theory, the hypothesis that the items adequately represent the construct, which involves soliciting opinions from individuals who do not yet form a representative population sample to construct such an instrument (Pasquali, 2010).

In order to measure the content validation coefficient (CVC) for each questionnaire item, the following criteria were adopted: (1) clarity of language; (2) practical pertinency; and (3) theoretical relevance. In addition, the degree of agreement between judges was measured for each item.

Table 1 displays the scores given by judges with respect to all items. Scores range from 1 to 5 , where: 1 means "very little"; 2 denotes "little"; 3 stands for "moderate"; 4 means "a lot"; and 5 denotes "very much". The items evaluated (1,2, and 3) were: (1) clarity of language, so as to assess whether the language in the item is sufficiently clear and appropriate for the profile of the sample of organizations in the study; (2) practical pertinence, evaluating whether the item proposed is pertinent to the profile of the research sample; and (3) relevance to innovation, examining whether the item is representative for the purposes of measuring the phenomenon.

The initial instrument developed from the literature review and collection of qualitative data comprised 180 items. After the first round of validation by judges, 131 items remained while the final, validated instrument consisted of 65 items, applied to 335 respondents. Data were treated via the exploratory factorial analysis technique, using SPSS 19.0.

\section{Data Analysis}

\section{Factorial Analysis}

To carry out this analysis, as recommended by Hair et al. (2009), the sample should include over 50 respondents, though at least 100 cases are advisable to guarantee more robust results, paying attention to:

(1) The degree of the data's factorability, excluding indexes below 0.30 , where over $50 \%$ of the data matrix should display results above 0.30 ;

(2) Hair et al. (2009) and Tabachnick and Fidell (1989) recommended that omitted data should represent below $5 \%$ or $10 \%$ of the total;

(3) The normality of data via histograms; 
(4) Extreme cases, excluding cases that present as outliers, although in factorial analysis, variables presenting very disparate data tend to entail low factorial loads;

(5) The Kaiser-Meyer-Olklin (KMO) test, whereby excellent premises for generating factors are typified by indexes approaching "1". Pasquali (2010) suggested the following scale to interpret the value of the KMO statistic: $0.90-1=$ excellent; $0.80-0.89=$ good; $0.70-0.79=$ average; $0.60-0.69=$ mediocre; $0.50-0.59=$ poor; and $0-0.49=$ inadequate;

(6) Bartlett's sphericity test (BST), where $(p<0.05)$ must be statistically significant.

In view of these presuppositions, an initial inspection was carried out of the matrix and factorability potential by analyzing the main components. In the correlation matrix, the magnitude of the correlations' coefficients was examined. Further, it was verified that almost $100 \%$ of the values were above 0.30 , while the average for correlations was over 0.50, showing the matrix to be factorable, following Hair et al. (2009).

Both the KMO test and BST were carried out. The matrix revealed that $\mathrm{KMO}=0.977$, representing a high capacity for factorability, whereas the Bartlett index was $25,607,904$, reflecting a low probability that the population matrix could be an identity matrix.

An analysis was performed of the commonalities for the 65 variables that made up the final instrument applied, so as to measure the regression index of variables, taking each one as both a dependent and an independent variable. Since no extreme values were found, the analysis of this premise was positive, as no problems with commonalities were verified.

The main components analysis was used for initial estimates of the number of factors, as outlined in Table 1 , in order to verify the variance explained and the eigenvalues. Based on the assessment of the eigenvalues, the database indicates the existence of up to six factors.

Table 1, entitled Total Explained Variance, shows the amount of proper values or autovalues (eigenvalues) superior to 1 . Another step is the variance explained by the factor, which must be at least $3 \%$. Eigenvalues are the sum of the column of factorial loads squared for a factor, also known as the latent root. This represents the amount of variance explained by a factor. According to the explained variance, there are two factors in the example under analysis. Yet the eigenvalues analysis shows that there are up to six factors. Drawing on analysis of the Scree Plot graph, the basis could reveal up to three factors.

Table 1

\section{Explained Variance of the Factors}

\begin{tabular}{|c|c|c|c|c|c|c|}
\hline \multirow{2}{*}{ Component } & \multicolumn{3}{|c|}{ Initial eigenvalues } & \multicolumn{3}{|c|}{ Extraction sums of squared loadings } \\
\hline & Total & Variance \% & Cumulative $\%$ & Total & Variance $\%$ & Cumulative \% \\
\hline 1 & 41.083 & 63.204 & 63.204 & 41.083 & 63.204 & 63.204 \\
\hline 2 & 2.279 & 3.506 & 66.711 & 2.279 & 3.506 & 66.711 \\
\hline 3 & 1.827 & 2.810 & 69.521 & 1.827 & 2.810 & 69.521 \\
\hline 4 & 1.573 & 2.419 & 71.940 & 1.573 & 2.419 & 71.940 \\
\hline 5 & 1.131 & 1.740 & 73.680 & 1.131 & 1.740 & 73.680 \\
\hline 6 & 1.094 & 1.682 & 75.362 & 1.094 & 1.682 & 75.362 \\
\hline
\end{tabular}

In order to generate congruence between the analysis of the factorial loads and the theoretical direction of the potential factors, the model with six factors was chosen for examination. It can explain up to $75.36 \%$ of the phenomenon. 


\section{Extraction of Factors}

Model with six factors. In the model of six factors showed in Figure 2, all 65 variables presented a factorial load of above 0.30 (the cut-off index for maintaining a variable) and the theoretical direction of the grouping of factors was observed.

The internal consistency of Factor 1 was evaluated, presenting a Cronbach's alpha $(\alpha)$ score of 0.985 , which is considered excellent according to Hair et al. (2009). In addition, all the factor's items were maintained so as not to compromise the alpha decrease.

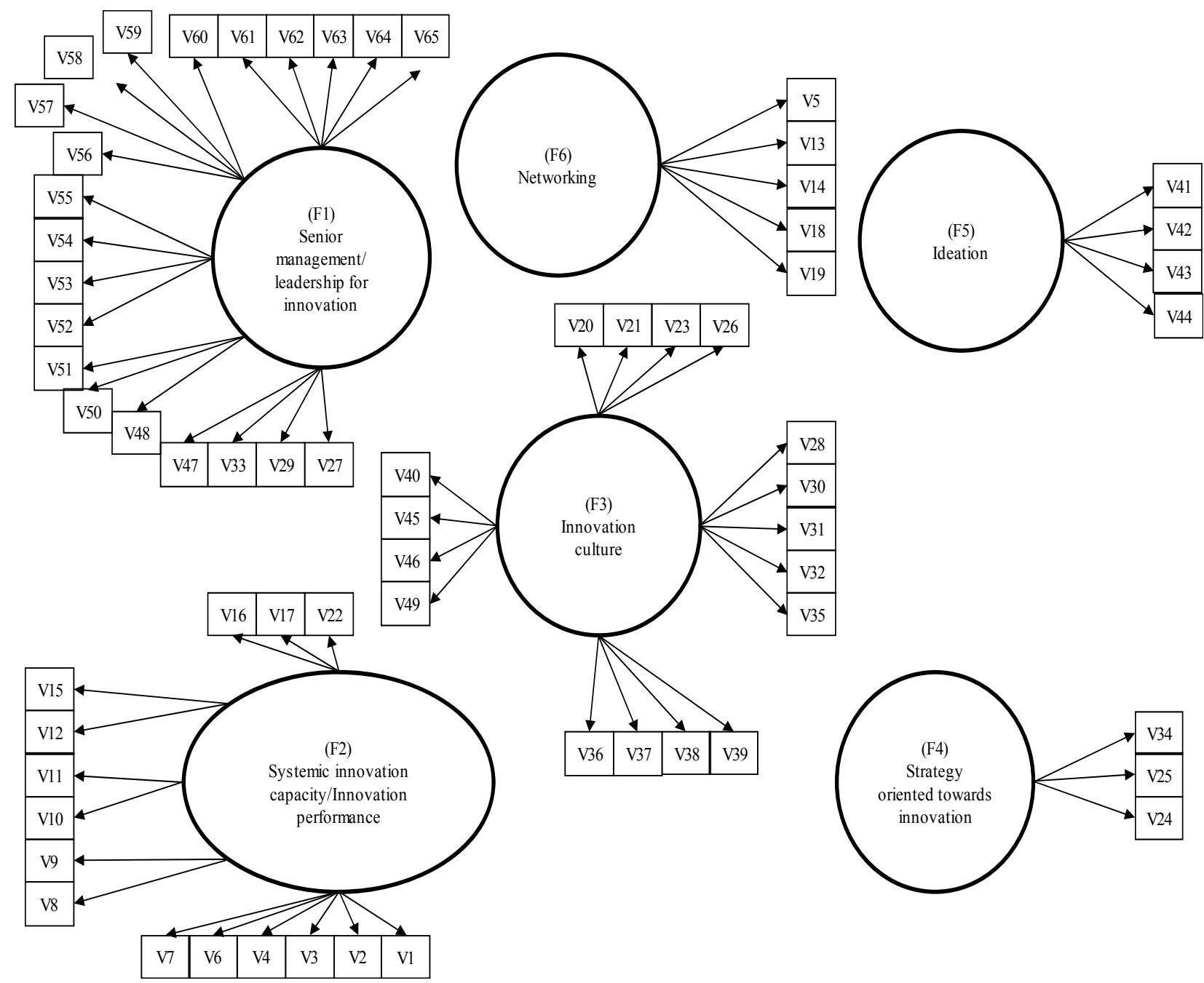

Figure 2. Factorial model.

Factor 2 presented a Cronbach's alpha $(\alpha)$ internal consistency score of 0.958 for the 15 items, which is excellent according to Hair et al. (2009). Again, all the factor's items were maintained so as not to compromise the alpha decrease. Factor 3 presented a Cronbach's alpha $(\alpha)$ internal consistency score of 0.972 for the 17 items and none was excluded. Factor 4 presented a Cronbach's alpha $(\alpha)$ internal consistency score of 0.856 , also conforming to the adequacy parameters set out by Hair et al. (2009) for the three items. Factor 4 presented a Cronbach's alpha $(\alpha)$ score of 0.922 for four items. Finally, the sixth factor presented Cronbach's alpha $(\alpha)$ score of 0.933 for five items. Table 2 displays the six factors found for this model. 
Table 2

List of Research Factors

\begin{tabular}{|l|l|}
\hline No. & Factors \\
\hline F1 & Senior management/leadership for innovation \\
\hline F2 & Systemic innovation capacity/innovation performance \\
\hline F3 & Innovation culture \\
\hline F4 & Strategy oriented towards innovation \\
\hline F5 & Ideation \\
\hline F6 & Networking \\
\hline
\end{tabular}

Note. Source: developed by the authors.

Factor 1, leadership, concerns the ability of managers at organizations to direct changes, seek solutions, and develop partnerships. Factor 2, systemic innovation capacity, examines the existence of management models, control methods, and work standards. Factor 3, innovation culture, takes into account the formal and informal practices, as well as the RD\&I policies, implemented at the organization. Factor 4, strategy oriented towards innovation, refers to the explicit presence of strategic planning by the company, of strategies oriented towards product, services, organizational and business innovation, in addition to their respective indicators. Factor 5, ideation, denotes the mobilization of individuals and teams to try out and apply new ideas that are capable of generating competitive gains with sustainable development. Networking (Factor 6) concerns the existence of inter-organizational relations for the development of projects through cooperation.

Table 3 displays the relationship between this model's factors and the factors found during the literature review.

Table 3

Relationship Between Research Factors and Literature Review

\begin{tabular}{|c|c|}
\hline $\begin{array}{l}\text { Integrated models (Chen, Tsou, \& Huang, 2009; Gebauer, Krempl, Fleisch, \& Friedli, 2008; Jong } \\
\text { \& Vermeulen, 2003) }\end{array}$ & Research factors \\
\hline Workers' involvement at the front line & - \\
\hline Information sharing & - \\
\hline Multifunctional teams & - \\
\hline Tools & - \\
\hline Information technology & - \\
\hline Internal organization & F3 \\
\hline Training and education & F3 \\
\hline Presence of excellence in service & - \\
\hline Autonomy of employees & - \\
\hline Market research & F3 \\
\hline Market test & F3 \\
\hline Strategic focus & F4 \\
\hline External contacts & F6 \\
\hline Availability of resources & - \\
\hline Managerial support & F1 \\
\hline
\end{tabular}

Note. Source: developed by the authors.

Model with five factors. In the model of five factors showed in Figure 3, the 65 variables presented a factorial load of above 0.30 and the theoretical direction of the grouping was observed. 


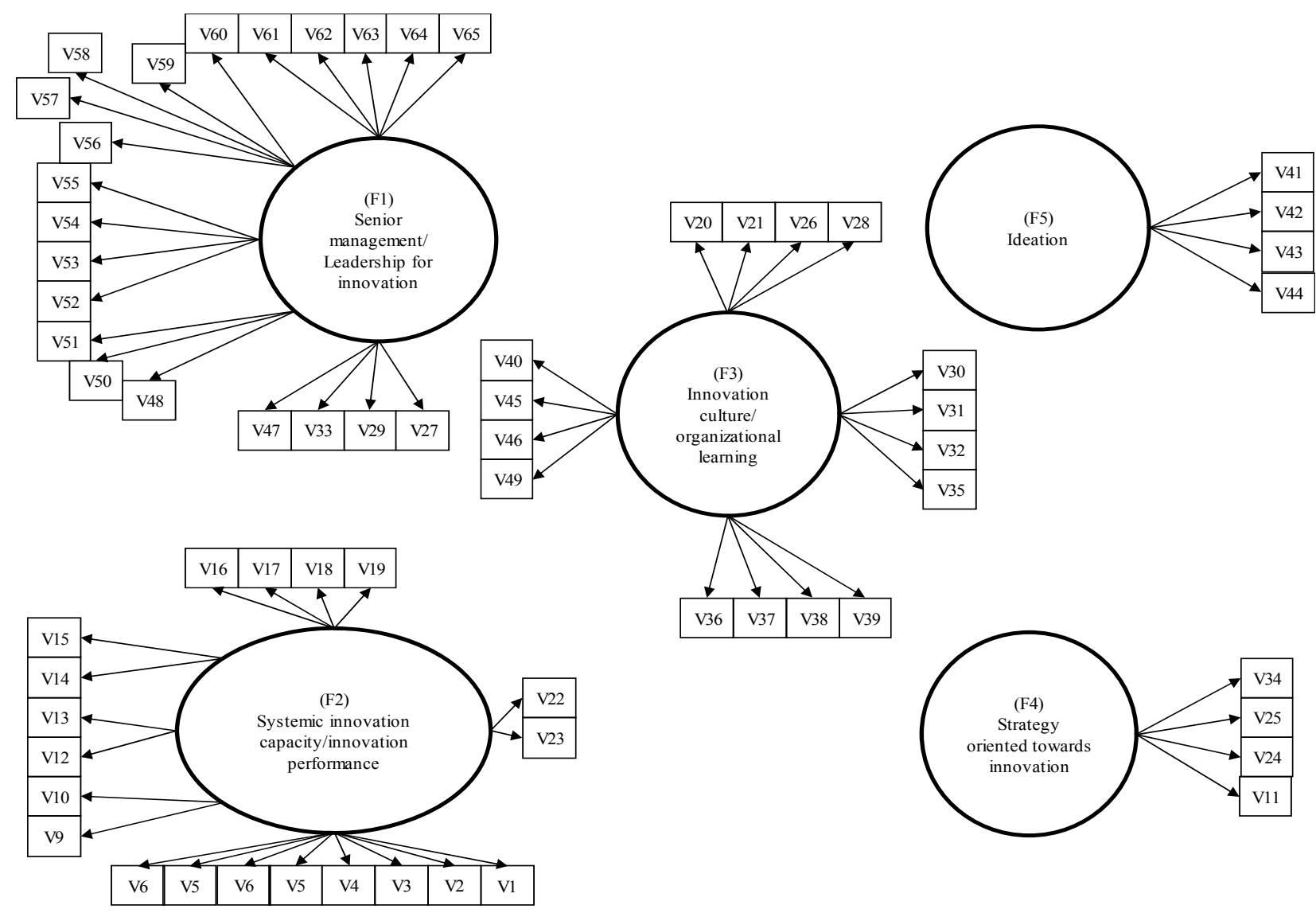

Figure 3. Factorial Model II.

Table 4 displays the relationship between this model's factors and the factors found during the literature review.

Table 4

Relationship Between the Research Factors and Literature Review

\begin{tabular}{|l|l|}
\hline Integrated models (Chen et al., 2009; Gebauer et al., 2008; Jong \& Vermeulen, 2003) & Research factors \\
\hline Workers' involvement at the front line & - \\
\hline Information sharing & - \\
\hline Multifunctional teams & - \\
\hline Tools & - \\
\hline Information technology & - \\
\hline Internal organization & F3 \\
\hline Training and education & $\mathrm{F} 3$ \\
\hline Presence of excellence & - \\
\hline Autonomy of employees & - \\
\hline Market research & $\mathrm{F} 3$ \\
\hline Market test & $\mathrm{F} 3$ \\
\hline Strategic focus & $\mathrm{F} 4$ \\
\hline External contacts & - \\
\hline Availability of resources & - \\
\hline Managerial support & $\mathrm{F} 1$ \\
\hline
\end{tabular}

Note. Source: developed by the authors. 
The internal consistency of Factor 1 was evaluated and it presented a Cronbach's alpha $(\alpha)$ score of 0.985 , which is considered excellent, in line with Hair et al. (2009). In addition, all the factor's items were maintained so as not to compromise the alpha decrease. With regard to Factor 2, the internal consistency according to Cronbach's alpha $(\alpha)$ was 0.970 for the 20 items and all the factor's items were maintained so as not to compromise the alpha decrease. Factor 3 presented a Cronbach's alpha $(\alpha)$ score of 0.971 for the 16 items and none was excluded. Factor 4 presented a Cronbach's alpha $(\alpha)$ score of 0.855 , in line with the adequacy parameters set out by Hair et al. (2009) for the four items concerned. Again, in this model, Factor 5 presented a Cronbach's alpha $(\alpha)$ score of 0.922 for four items. Table 5 displays the five factors found for this model.

Table 5

List of Research Factors

\begin{tabular}{|l|l|}
\hline No. & Factors \\
\hline F1 & Senior management/leadership for innovation \\
\hline F2 & Systemic innovation capacity/innovation performance \\
\hline F3 & Innovation culture/organizational learning \\
\hline F4 & Strategy oriented towards innovation \\
\hline F5 & Ideation \\
\hline
\end{tabular}

Note. Source: developed by the authors.
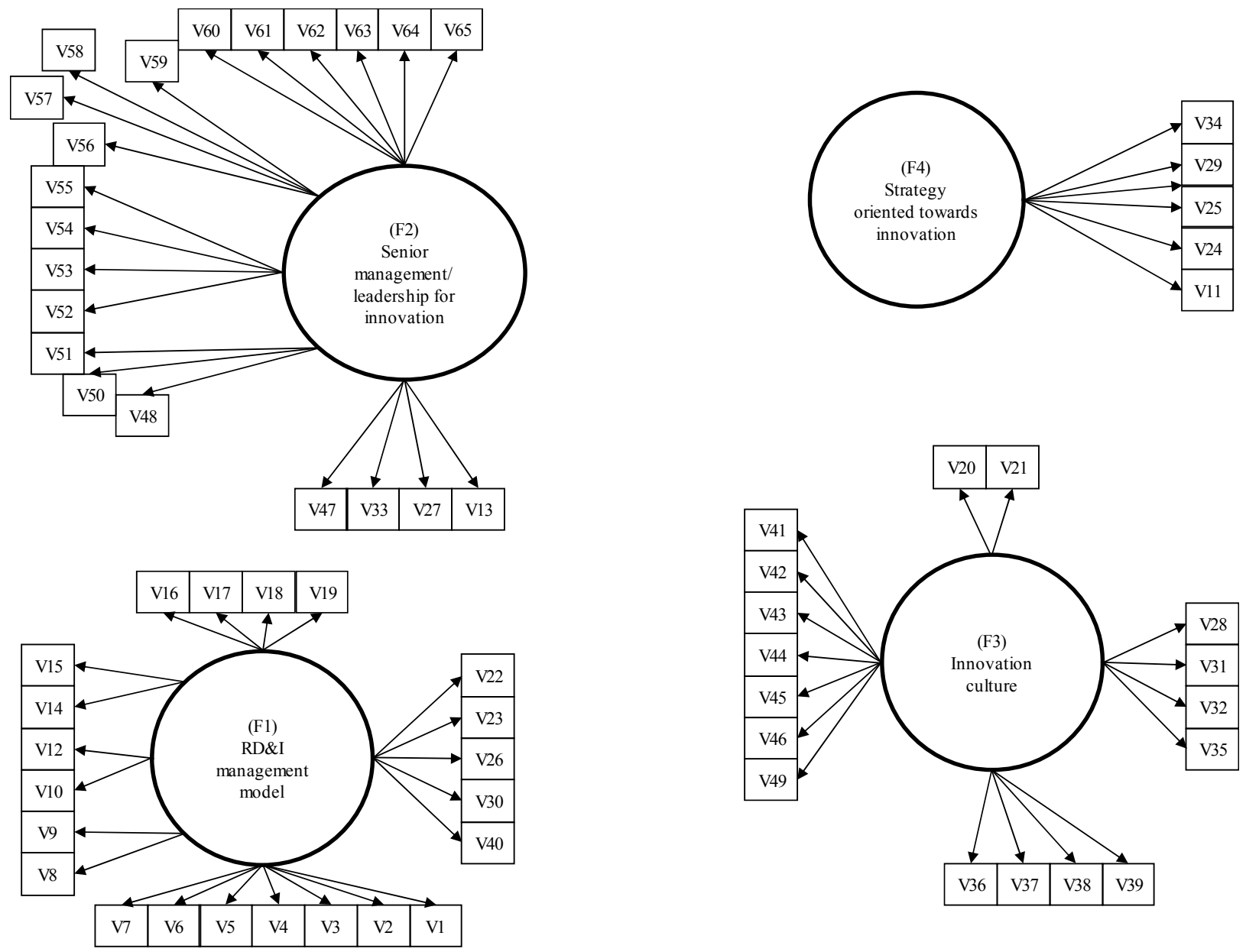

Figure 4. Factor Model III. 
Model with four factors. In the model of four factors showed in Figure 4 above, the 65 variables presented a factorial load above 0.30 and the theoretical direction of the grouping of factors was observed.

The internal consistency of Factor 1 was evaluated, presenting a Cronbach's alpha $(\alpha)$ score of 0.974 for 22 items. With regard to Factor 2, the internal consistency according to Cronbach's alpha $(\alpha)$ was 0.983 for the 21 items and all the factor's items were maintained so as not to compromise the alpha decrease. Factor 3 presented a Cronbach's alpha $(\alpha)$ score of 0.968 for the 17 items and none was excluded. Factor 4 presented a Cronbach's alpha $(\alpha)$ score of 0.896 , meeting the adequacy parameters set out by Hair et al. (2009) for its five items.

Table 6 displays the relationship between this model's factors and the factors found during the literature review.

Table 6

Relationship Between the Research Factors and Literature Review

\begin{tabular}{|l|l|}
\hline Integrated models (Chen et al., 2009; Gebauer et al., 2008; Jong \& Vermeulen, 2003) & Research factors \\
\hline Workers' involvement at the front line & - \\
\hline Information sharing & - \\
\hline Multifunctional teams & - \\
\hline Tools & - \\
\hline Information technology & - \\
\hline Internal organization & $\mathrm{F} 3$ \\
\hline Training and education & $\mathrm{F} 3$ \\
\hline Presence of excellence in service & - \\
\hline Autonomy of employees & - \\
\hline Market research & $\mathrm{F} 3$ \\
\hline Market test & $\mathrm{F} 3$ \\
\hline Strategic focus & $\mathrm{F} 4$ \\
\hline External contacts & - \\
\hline Availability of resources & - \\
\hline Managerial support & $\mathrm{F} 1$ \\
\hline
\end{tabular}

Note. Source: developed by the authors.

Table 7 below displays the four factors found for this model.

Table 7

List of Research Factors

\begin{tabular}{|l|l|}
\hline No. & Factors \\
\hline F1 & Senior management/leadership for innovation \\
\hline F2 & Systemic innovation capacity/innovation performance \\
\hline F3 & Innovation culture \\
\hline F4 & Strategy oriented towards innovation \\
\hline
\end{tabular}

Note. Source: developed by the authors.

Model with three factors. In the model of three factors showed in Figure 5, the internal consistency of Factor 1 was evaluated, presenting a Cronbach' alpha $(\alpha)$ score of 0.975 for 24 items. With regard to Factor 2 , the internal consistency according to Cronbach's alpha $(\alpha)$ was 0.982 for the 19 items and all the factor's items were maintained so as not to compromise the alpha decrease. Factor 3 presented a Cronbach's alpha $(\alpha)$ score of 0.974 for the 22 items and none was excluded. 

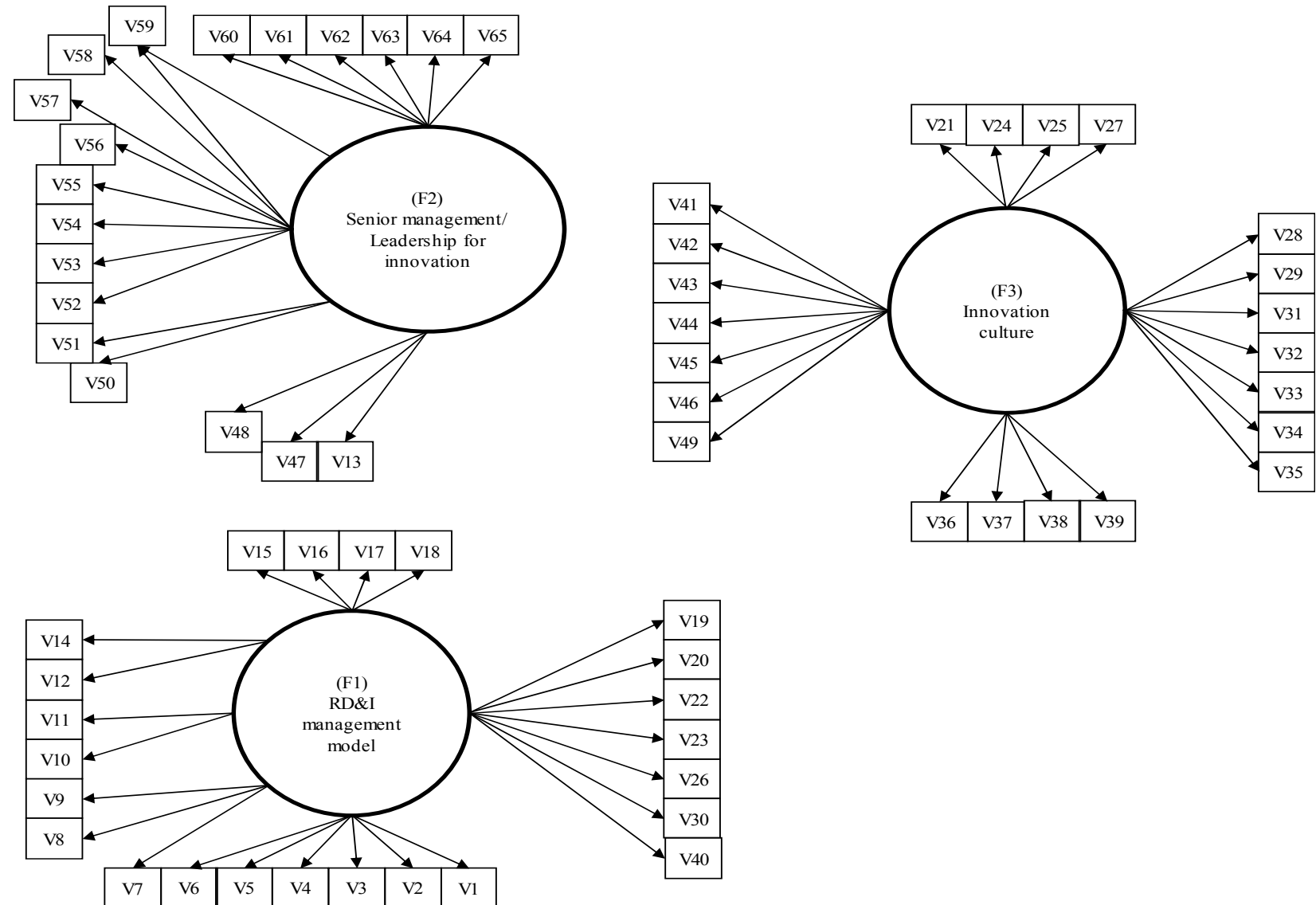

Figure 5. Factor Model IV.

Table 8 displays the relationship between this model's factors and the factors found during the literature review.

Table 8

Relationship Between the Research Factors and Literature Review

\begin{tabular}{|l|l|}
\hline Integrated models (Chen et al., 2009; Gebauer et al., 2008; Jong \& Vermeulen, 2003) & Research factors \\
\hline Workers' involvement at the front line & - \\
\hline Information sharing & - \\
\hline Multifunctional teams & - \\
\hline Tools & - \\
\hline Information technology & - \\
\hline Internal organization & F3 \\
\hline Training and education & F3 \\
\hline Presence of excellence in service & - \\
\hline Autonomy of employees & - \\
\hline Market research & $\mathrm{F} 3$ \\
\hline Market test & $\mathrm{F} 3$ \\
\hline Strategic focus & - \\
\hline External contacts & - \\
\hline Availability of resources & - \\
\hline Managerial support & $\mathrm{F} 2$ \\
\hline Note. Sol cor
\end{tabular}

Note. Source: developed by the authors. 
Table 9 below displays the three factors found for this model.

Table 9

List of Research Factors

\begin{tabular}{|l|l|}
\hline No. & Factors \\
\hline F1 & RD\&I management model \\
\hline F2 & Senior management/leadership for innovation \\
\hline F3 & Innovation culture \\
\hline
\end{tabular}

Note. Source: developed by the authors.

Model with two factors. The model of two factors showed in Figure 6 is made up of 60 variables, all of which presented factorial loads of above 0.30 . The theoretical direction of the grouping of factors was observed.
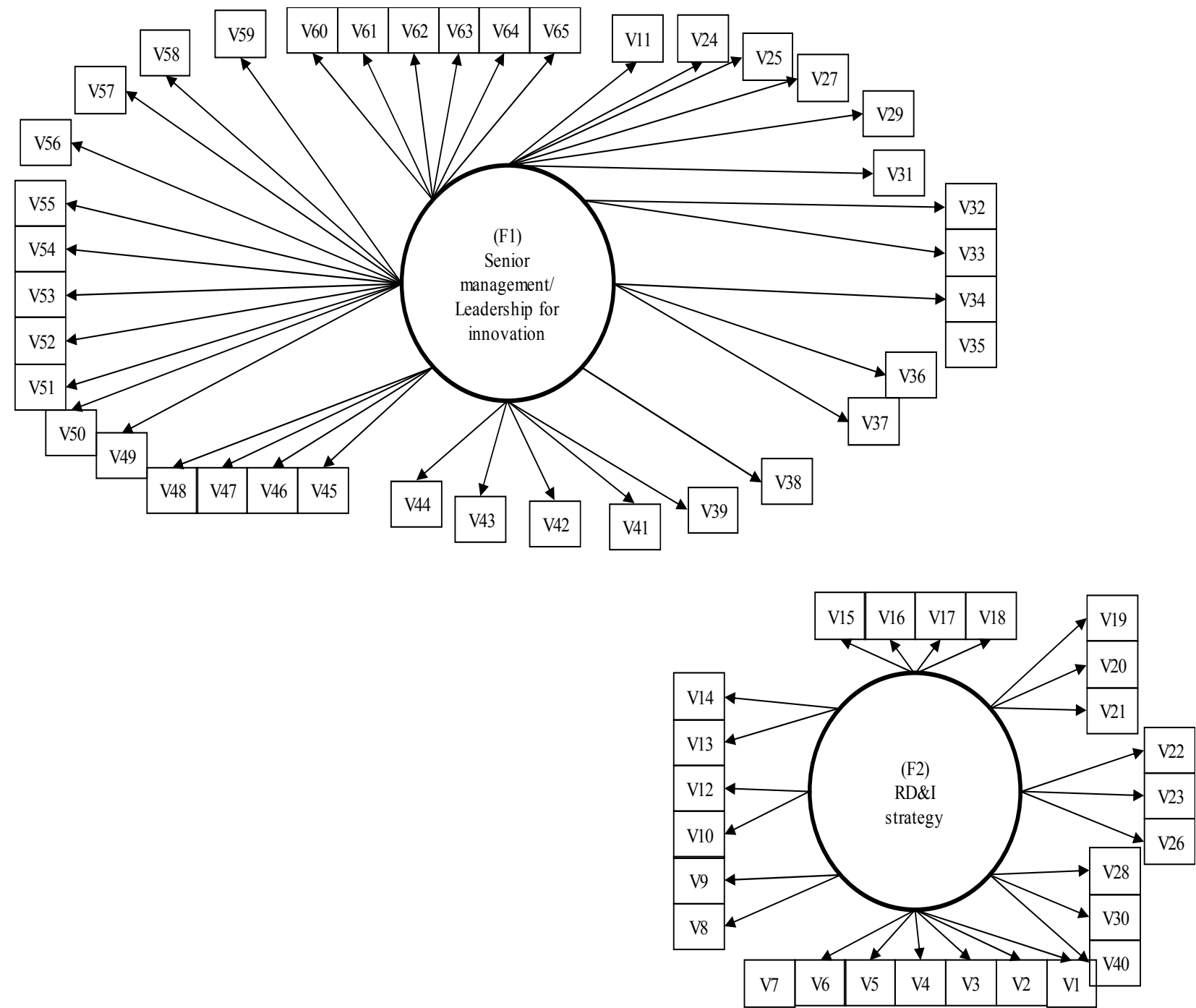

Figure 6. Factor Model V.

The internal consistency of Factor 1 was evaluated, presenting a Cronbach's alpha $(\alpha)$ score of 0.987 for 34 items. With regard to Factor 2, the internal consistency according to Cronbach's alpha $(\alpha)$ was 0.977 for 26 items. 
Table 10 displays the relationship between this model's factors and the factors found during the literature review.

Table 10

Relationship Between the Research Factors and Literature Review

\begin{tabular}{|l|l|}
\hline Integrated models (Chen et al., 2009; Gebauer et al., 2008; Jong \& Vermeulen, 2003) & Factors \\
\hline Workers' involvement at the front line & - \\
\hline Information sharing & - \\
\hline Multifunctional teams & - \\
\hline Tools & - \\
\hline Information technology & - \\
\hline Internal organization & - \\
\hline Training and education & - \\
\hline Presence of excellence in service & - \\
\hline Autonomy of employees & - \\
\hline Market research & - \\
\hline Market test & - \\
\hline Strategic focus & $\mathrm{F} 2$ \\
\hline External contacts & - \\
\hline Availability of resources & - \\
\hline Managerial support & - \\
\hline
\end{tabular}

Note. Source: developed by the authors.

Table 11 displays the two factors found for this model.

Table 11

List of Research Factors

\begin{tabular}{|l|l|}
\hline No. & Factors \\
\hline F1 & RD\&I management model \\
\hline F2 & RD\&I strategy \\
\hline
\end{tabular}

Note. Source: developed by the authors.

\section{Results and Conclusions}

From the literature review undertaken, attention was drawn to a set of international studies that investigated forerunners of organizational innovation (Chen et al., 2009; Gebauer et al., 2008; Jong \& Vermeulen, 2003). The consolidated results point to 15 forerunners of innovation: workers' involvement at the front line, information sharing, multifunctional teams, tools, information technology, internal organization, training and education, presence of excellence in service, autonomy of employees, market research, market test, strategic focus, external contacts, availability of resources, and managerial support. The following are definitions for these factors:

(1) Workers' involvement at the front line: service provider's ability to act directly, together with the client user of the organization;

(2) Information sharing: sharing of information between the team for project development, products and services, and workers at the front line who mention clients' demands; 
(3) Multifunctional teams: integration of employees with distinct and complementary skills into one project or work groups;

(4) Tools: availability of instruments needed to deliver a service;

(5) Information technology: knowledge applied to work processes that organize the flow of data and information;

(6) Internal organization: existence of specialized innovation areas or processes, task rotation among employees, dedication to tasks outside of routine, permission to try out new ideas at the organization;

(7) Training and education: qualification of employees in business innovation processes;

(8) Excellence of service: work standards defined with service level agreements. Involvement of collaborators, especially those who have direct contact with service users. The knowledge of collaborators can be useful in generating information on the requirements and functions of the services provided, enabling an adequate level of service personalization and recognition of market opportunities;

(9) Autonomy of employees: employer's ability to take decisions exercising responsibility and authority, without consulting other individuals or management;

(10 and 11) Market research and tests: survey of clients' needs to enhance understanding of the market's behavior before and after a service is launched. These are inputs for the design and redefinition of service packages to cater for different client profiles. Research and tests enable adjustments to service, verifying its suitability for clients' needs throughout the development process;

(12) Strategic focus: ability to spot opportunities and essential competitive risks; systematized management processes for relationships with citizens and users; medium- and long-term planning; vision of sustainability;

(13) External contacts: relationship agreements with clients, providers, partners with systematized learning practices;

(14) Availability of resources: other resources for innovation projects such as people, management models, methods, and work standards;

(15) Managerial support: managers' incentive to encourage creativity in employees when searching for new business opportunities, motivating employees to take on risks without fear of punishment.

The work undertaken offers theoretical and practical contributions for studying innovation, since new factors were observed in the five potential models, in addition to those highlighted in the literature review. The model with three factors (RD\&I management model, senior management/leadership for innovation, and innovation culture) reveals a high internal consistency for all factors and an explained variance of $69.52 \%$ for the phenomenon, showing conformity with the literature. However, it is necessary to test, via confirmatory factorial analysis, whether adjustment indexes are compatible with theory. This analysis should be carried out for the five models.

\section{Limitations of the Study}

The results obtained also have limitations as the study is transversal, while undertaking the investigation through a longitudinal approach would likely have led to factors composed of new items. The results should not be generalized with respect to the Brazilian context, though the organizations and subjects are strongly represented within the respective sectors. 
There was a bias in selecting the sample of organizations, since the FNQ concocted the Technical Group for Innovation based on proven management practices that adhere better to the Management Excellence Model, administered by the FNQ itself.

Even with a defined scope to build survey respondents' profiles, there is no guarantee that the judgments made by participants represent reliable indexes regarding the expression of organizational innovation drivers.

\section{Contribution of Study}

Given the relative shortage of empirical studies on innovation in Brazil, borne out in the document analysis, the study offers theoretical, methodological, and practical contributions for this field of research.

As mentioned by several respondents in the open questions section, participation in the survey generated reflections on prospects for innovation in industry and the service sector, including the public sector. Another contribution is the development of a scale to measure the propulsion of organizational innovation.

\section{Agenda for Future Studies}

It is suggested that the study be continued using confirmatory factorial analysis for the models obtained at the exploratory stage. Results should be assessed in accordance with the following premises set out by Hair et al. (2009):

(1) Chi-squared ratio/degrees of freedom $(\mathrm{X} 2 / \mathrm{gl})$ values of below 5.00 demonstrate the model's suitability to describe data;

(2) Comparative Fit Index (CFI); this index adjusts incrementally. CFI values below 0.90 are generally not associated with a model that adjusts well;

(3) The Tucker-Lewis Index (TLI) is conceptually similar to the CFI. Typically, models that adjust well have values close to 1 ;

(4) The Root Mean Square Error of Approximation (RMSEA) assesses the model's error in relation to the saturated model with the same dataset. The smaller the index value, the better the model is adjusted, preferably below 0.1 .

\section{References}

Birkinshaw, J., Hamel, G., \& Mol, M. J. (2008). Management innovation. Academy of Management Review, 33(4), 825-845.

Chen, J., Tsou, H. T., \& Huang, A. Y. (2009). Service delivery innovation: Antecedents and impact on firm performance. Journal of Service Research, 12(1), 36-55.

Gebauer, H., Krempl, R., Fleisch, E., \& Friedli, T. (2008). Innovation of product-related services. Managing Service Quality, $18(4), 387-404$.

Hair, J. F., Black, W. C., Babin, B. J., Anderson, R. E., \& Tatham, R. L. (2009). Análise multivariada de dados. Porto Alegre: Bookman.

Hernandéz-Nieto, R. A. (2002). Contribuiciones al análisis estatístico. Mérida: Universidad de Los Andes/IESINFO.

Jong, J. P. J., \& Vermeulen, P. A. M. (2003). Organizing successful new service development: A literature review. Management Decision, 41(9), 844-858.

OECD. (2005). The Oslo manual (3rd ed.). FINEP/OECD.

Pasquali, L. (2010). Testes referentes a construto: teoria e modelo de construção. In L. Pasquali et al. (Eds.), Instrumentação psicológica: fundamentos e práticas. Porto Alegre: Artmed.

Tabachnick, B. G., \& Fidell, L. S. (1989). Using multivariate statistics. New York, NY: Harper Collins Publishers. 